\section{Summary and Conclusions}

The mortality in a series of 25 infants with myelomeningocele closed within the first 24 hours of birth was $12 \%$ over the first three months.

Neurological assessment of the survivors with particular attention to leg movements has indicated that spinal reflex phenomena are common, and that, though there may be apparent improvement in some cases within the first few weeks after operation, the later results show that there is no significant increase in useful leg function compared with the preoperative levels.

Early closure would appear to have prevented the death of these infants, and to have preserved the useful leg movements with which they were born, but not to have led to any significant recovery.
We wish to thank the consultant paediatricians in the East Arglian Region for their help in this study, and in the management of these infants ; Dr. D. M. T. Gairdner and Dr. J. D. Roscoe (Cambridge), Dr. R. M. Mayon-White (Ipswich), Dr. B. W. Powell (Peterborough), Dr. J. F. P. Quinton (Norwich), and Dr. R. C. Roxburgh (King's Lynn).

\section{REFERENCES}

Doran, P. A., and Guthkelch, A. N. (1961). F. Neurol. Neurosurg. Psychiat., 24, 331.

Guthkelch, A. N. (1962a). Ibid., 25, 137.

- (1962b). Brit. F. prev. soc. Med., 16, 159

(1964). Develop. Med. child Neurol., 6, 264

(1965). Acta neurochir (Wien), 13,407.

Laurence, K. M. (1964). Arch. Dis. Childh., 39, 41.

- (1965). Develop. Med. child Neurol., Suppl. No. 11, p. 10.

Record, R. G. and McKeown, T. (1949). Brit. J. prev. soc. Med., 3,183

Record, R. G., and Mckeown, T. (1949). Brit. F. prev. soc. M. M. (1963) Arch. Dis. Childh., 38, 18.

Stevenson, A. C., and Warnock, H. A. (1959). Ann. hum. Genet., 23, 382 .

\title{
Scabies: Another Epidemic?
}

\author{
ALAN B. SHRANK,* M.A., B.M., B.CH., M.R.C.P.; SUZANNE L. ALEXANDER, † M.B., B.S.
}

Brit. med. F., 1967, 1, 669-671

Several infectious diseases are legally notifiable so that epidemics can be readily detected and appropriate steps taken by public health authorities. Some infectious diseases, such as scabies, are not notifiable, and fluctuations in their incidence may be appreciated only by those treating them, and an epidemic may remain unrecognized until it is well advanced. This paper reports a recent rise in the prevalence of scabies at St. John's Hospital for Diseases of the Skin, London, where nearly 15,000 new outpatients are seen each year. 'An attempt is made to account for the rise. A few case histories are recorded, in which the diagnosis of scabies had been overlooked by the referring doctor, in order to emphasize the serious consequences of mistaken diagnosis and the need to consider this diagnosis in anyone with pruritus.

\section{Method}

The number of patients diagnosed as having scabies as well as syphilis and pediculosis and the total number of new outpatients seen each year since 1952, when the diagnostic index began, were recorded. The case notes of those seen in 1961 and in 1965 were examined, and those in whom the diagnosis was proved by microscopy were selected for study. 1961 was chosen because the incidence that year was similar to the preceding eight and the subsequent two years, while 1965 was chosen because the rise was most pronounced that year. The age, sex, marital status, whether the referring doctor had suspected scabies, and whether contacts had also attended the hospital were recorded.

\section{Results}

The incidence of scabies can be seen in Table $I$; the average was $0.9 \%$ (range 0.6 to $1.2 \%$ ) of all new patients seen from 1952 until 1963 , but in 1964 it rose to $1.4 \%$, in 1965 to $2.1 \%$, and in 1966 to $2.4 \%$. In 1961, of the 118 thought to have scabies

\footnotetext{
- Dermatologist, Royal Salop Infirmary, Shrewsbury, Shropshire. Late Tutor in Dermatology, St. John's Hospital for Diseases of the Skin, London W.C.2.

+ Research Associate, Guy's Hospital, London S.E.1 ; Clinical Assistant,
} St. John's Hospital for Diseases of the Skin, London W.C.2. proof was obtained in 103, of whom $58(57 \%)$ were men, while in 1965256 of the 293 were proved to have scabies, of whom $156(61 \%)$ were men. Fig. 1 gives more data for those proved to have scabies; the age groupings are arbitrary. The major increase is in single young people aged 16 to 21 , sixfold in the

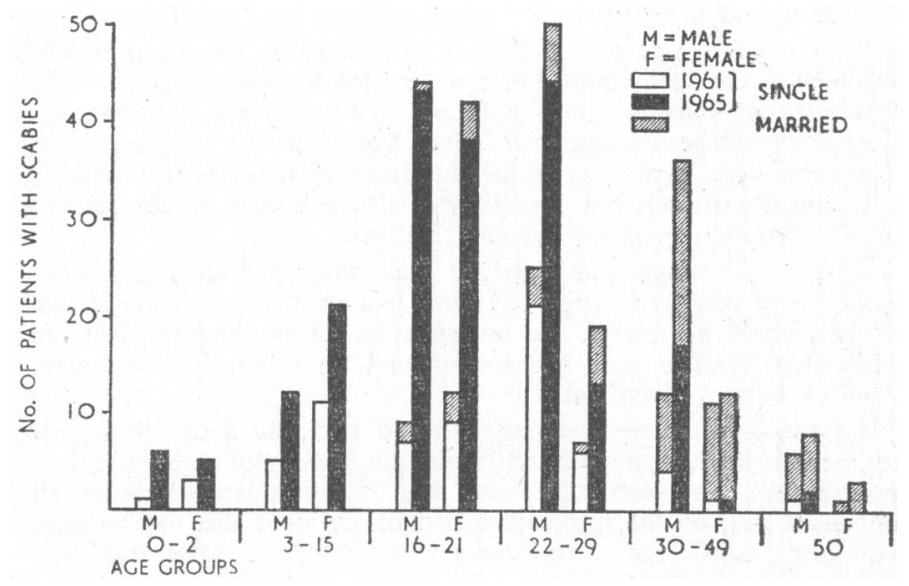

Fig. 1 shows the numbers of new patients with scabies attending St. John's Hospital for Diseases of the Skin, London, in 1961 and 1965 according to age, sex, and marital status.

TABLE I.-Numbers of Outpatients with Scabies, Pediculosis, and Syphilis and the Total New Outpatients Attending St. Fohn's Hospital for Diseases of the Skin, London, from 1952 to 1966

\begin{tabular}{c|c|c|c|c} 
Year & Scabies & Pediculosis & Syphilis & $\begin{array}{c}\text { Total New } \\
\text { Outpatients }\end{array}$ \\
\hline 1952 & 128 & - & -18 & 18,628 \\
1953 & 120 & 18 & 12 & 17,302 \\
1954 & 152 & 18 & 5 & 15,812 \\
1955 & 145 & 18 & 2 & 14,524 \\
1956 & 164 & 11 & 6 & 14,969 \\
1957 & 166 & 14 & 4 & 13,836 \\
1958 & 116 & 19 & 6 & 13,832 \\
1959 & 136 & 14 & 3 & 13,556 \\
1960 & 158 & 14 & 15 & 15,037 \\
1961 & 118 & $18(10)$ & 7 & 12,654 \\
1962 & 119 & $13(7)$ & 12,597 \\
1963 & 101 & $12(3)$ & 4 & 14,079 \\
1964 & 190 & $15(7)$ & 11 & 14,173 \\
1965 & 293 & $20(15)$ & $23(14)$ & 13,836 \\
\hline
\end{tabular}

Figures in parentheses $=$ numbers with phthiriasis. 
boys and fourfold in the girls ; twofold rises occurred in children aged 3 to 15 and in women aged 22 to 29 , and a threefold rise in men aged 30 to 49 .

The referring doctor suspected scabies in $50 \%$ of referrals in 1961 , in only $42 \%$ in 1965 , but more often in women in both years, but the differences are not statistically significant. In 1961 nine families with 22 affected members and in 1965 16 families with 41 affected members were seen.

\section{Case Histories}

In the following case histories scabies was diagnosed on the first hospital attendance and confirmed by microscopy.

Case 1.-A married woman aged 29 had generalized itching for five months, starting two weeks after she adopted an infant with " eczema" ; two months later her husband had also started to itch. They knew that the baby's true mother had had scabies. Topical corticosteroid therapy failed to relieve the baby's "eczema" or the patient's pruritus; she was given systemic corticosteroids with some benefit, and also referred for a psychiatric opinion. Doubt was cast upon the couple's suitability as foster parents in view of their presumed "nervous eczema." All had scabies.

Case 2.-A boy of 12 had had pruritus for eight months, which failed to respond to local and oral antihistamine preparations, topical corticosteroids, and five weeks' inpatient therapy with sedatives and occlusive tar bandages. Oral prednisone had been given, which suppressed the itching, so that the excoriations cleared, but the papular element persisted, and the pruritus and excoriations recurred when it was withdrawn. Acari were found on the patient, his brother aged 7 , a sister aged 5 , as well as on his mother.

Case 3.-A married woman aged 69 had had itching for six months, which she had attributed to nervousness after a road accident in which she had broken a leg. Symptoms began while her leg was in plaster in hospital. Tranquillizers and sedatives were of no benefit. An acarus was found on her hand. After treatment she continued to be anxious about her claim for compensation but she no longer had pruritus.

Case 4.-A single girl of 19 had had infantile eczema until the age of 8. On coming to London 18 months previously she had developed an itchy rash on her limbs. This was treated with coaltar paste bandages as well as sedatives, but to no effect. Outpatient treatment with benzyl benzoate emulsion cleared the infestation, but topical corticosteroid therapy was also necessary to control the irritant eruption produced by the treatment.

Case 5.-A single girl aged 23 was referred with a suggested diagnosis of contact eczema. She had had an itchy erythema on her breasts, under her corset, and on her arms for two months, but she knew that her flat mate had had scabies three months previously. Typical burrows were found.

Case 6.-A married woman aged 56 had had four admissions to mental institutions for schizophrenia, and still needed chlorpromazine. She had itched for four months, and, because an increased dose of chlorpromazine had not relieved this, readmission was being considered. An acarus was found, and after treatment the pruritus resolved.

\section{Discussion}

Results derived from hospital clinics may not reflect the situation in the general population, but there has been little change in the number of new patients referred to St. John's Hospital or in the proportion suspected of scabies, so the rise in scabies at the hospital probably parallels a rise in the general

TABLB II.-Numbers of Men with Scabies and the Total New Outpatients Attending the Whitechapel Clinic, London, Each Year from 1961 to 1965

\begin{tabular}{c|c|c|c}
\hline Year & Scabies & $\begin{array}{c}\text { Total New } \\
\text { Outpatients }\end{array}$ & $\begin{array}{c}\text { Percentage } \\
\text { With Scabies }\end{array}$ \\
\hline 1961 & 57 & 6,577 & 0.9 \\
1962 & 41 & 6,098 & 0.7 \\
1963 & 88 & 6,315 & $1 \cdot 4$ \\
1964 & 68 & 6,007 & 1.1 \\
1965 & 86 & 5,851 & 1.5 \\
\hline
\end{tabular}

population, though the magnitude may be different and related only to the London area. Supportive evidence that the rise is not confined to St. John's Hospital comes from the Whitechapel Clinic, the V.D. clinic of the London Hospital ; Table II shows a rise from $0.9 \%$ to $1.5 \%$ in the incidence of scabies in new patients $(0.01>\mathrm{P}>0.001)$. General practitioners and dermatologists in different parts of England, in personal communications, have reported scabies in areas free for years, and in increased numbers in some cities. This suggests that the rise may be general in England and may well be the start of an epidemic.

The groups that are most affected by the rise, as shown in Fig. 1, are those regarded by sociologists and venereologists as the " most sexually active," but this may only mean that in an epidemic these groups are at risk and the most likely to become infested. If a rise in promiscuity were primarily responsible for the rise in scabies an association with gonorrhoea or infectious syphilis would be expected. 'That this is not so is shown in Fig. 2, which charts data from St. John's Hospital on scabies and pediculosis with national data on gonorrhoea and infectious syphilis. Though promiscuity is no doubt a factor in the spread of scabies, other factors are more important in precipitating an epidemic. If the current acarus were more virulent or contagious the rise should be more prominent in those who acquire scabies by casual contact, but the proportion of children and familial cases in 1965 was no greater than in 1961. Nor is the current acarus more resistant to conventional therapy, because cures were always obtained when treatment was used correctly.

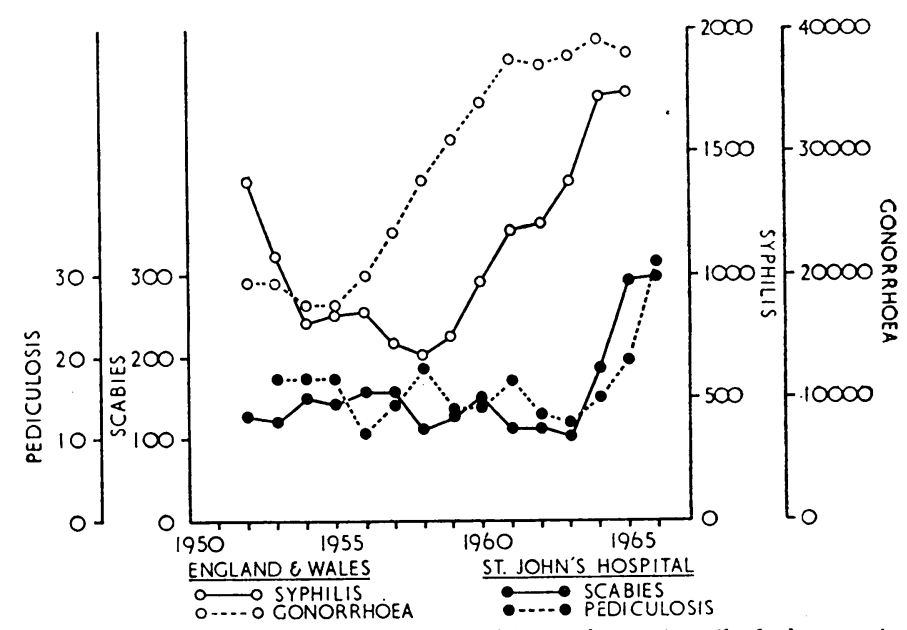

FIG. 2 shows the number of patients with scabies and pediculosis attending St. John's Hospital for Diseases of the Skin, London, and the number of patients with gonorrhoea and infectious syphilis attending Venereal Disease Clinics throughout England and
to 1966.

It is possible that immune mechanisms are involved. Mellanby (1943) thought that hypersensitivity to scabies developed after infestations lasting six months, since in second attacks itching began within hours instead of in two to six weeks as in first attacks; second attacks were difficult to induce ; fewer acari were present in established second attacks; and he obtained six positive reactions to intradermal injections of extracts of acari in seven subjects who had had scabies for over six months. Heilesen (1946) did not confirm Mellanby's observations, but he concluded that "in reinfected scabies patients the itching seems to set in especially early after infection, but this is not a constant feature, and itching at an early stage may also occur in individuals who have not had scabies previously," and " reinfected persons have more frequently than patients with first infections only slight sporadic eruptions."

Fig. 1 shows that those aged between 16 and 29 years form the largest group. At the end of an epidemic all those at risk in this age group would, if hypersensitivity occurs, be hypersensitive, 
and only those under 16 would remain non-sensitized; to replace the hypersensitive 16 to 29 age group by non-sensitive individuals would take 14 to 16 years. If hypersensitivity conferred a slight resistance to infestation or a lesser degree of contagion a gap of about 15 years might be expected between the end of one and the beginning of the next epidemic. Accurate data for past epidemics are not available, but Gray (1941) quotes the number of children treated for scabies at L.C.C. cleansing stations from 1919 to 1938, from which it is clear that the first world war epidemic declined rapidly in 1920, numbers remained low until 1930, when a slow rise began, and there was a precipitous rise in 1937. Hellier (1939), in Leeds, dates the rise in his practice from 1933. The gap here is from 10 to 14 years. The epidemic of the 1930's continued through the second world war and declined sharply in 1949 (Epstein, 1955). The rise reported in this paper thus started 15 years later and so further supports our hypothesis involving "herd resistance."

The case histories are a vivid reminder of the need for vigilance and for revision of diagnosis when supposedly effective therapy fails. The tendency in dermatological therapy to prescribe potent remedies, including systemic corticosteroids, before making a definitive diagnosis is to be deplored. In the case of scabies such a policy is imprudent and possibly dangerous, and leads to needless waste of medication, vain effort by the patient, waste of time of medical personnel, and increased cost to the taxpayer.

\section{Summary}

A continuing rise in the past three years in the incidence of scabies at St. John's Hospital for Diseases of the Skin, London, from an average of $0.9 \%$ of all new patients to $2.4 \%$ is reported. It is suggested that this heralds another epidemic.

From an analysis of the case notes and a review of past epidemics, the hypothesis that epidemics are directly related to " herd hypersensitivity" to scabies is presented ; it accounts for the gap of about 15 years between the end of one and the start of the next epidemic.

Thanks are due to the physicians at St. John's Hospital for Diseases of the Skin and to Dr. Ambrose King, of the Whitechapel Clinic, for permitting access to case notes, and to Dr. King and Dr. F. R. Bettley for advice on preparing this paper.

REPERENCES

Annual Report of the Chief Medical Officer for England and Wales (1952-1965). H.M.S.O., London.

Epstein, E. (1955). Arch. Derm., 71, 192

Gray, A. M. H. (1941). Brit. F. Derm., 53, 148

Heilesen, B. (1946). Acta derm.-venereol. (Stockh.), Suppl. No. 14.

Hellier, F. F. (1939). Trans. St. Fohn's Hosp. derm. Soc. (Lond.), 28, 52. Mellanby, K. (1943). Scabies. Oxford War Manuals. London.

\title{
Prescribing of Chloramphenicol in General Practice
}

\author{
T. W. MEADE,* B.M., M.R.C.P.
}

A study of prescribing by general practitioners revealed very wide individual differences for which no satisfactory explanations have so far been found (Lee, 1964 ; Weatherall, 1964 ; Draper, 1964 ; Lee, Draper, and Weatherall, 1965 ; Joyce, Last, and Weatherall, 1967). It is possible that such differences in prescribing are related to skill, training, or other aspects of the quality of general practice. Any attempt to measure these attributes must, if it is to be meaningful, employ an acceptable index; the prescribing of chloramphenicol may provide one. The present study was carried out at a time when the limited therapeutic usefulness and the dangers of this drug had been much publicized and were widely recognized (Wilson, 1956; Shaw and McLean, 1957 ; Registrar General, 1960 ; Brit. med. f., 1960, 1961). One of the annotations in the British Medical fournal just cited appeared at the beginning of the month in which the main part of the present study was carried out. It said: "The occurrence of aplastic anaemia ... is so dangerous . . . that many physicians feel it wise to avoid using the drug [chloramphenicol] systemically when any alternative effective therapy is available." In fact, since the first British cases of fatal aplastic anaemia due to chloramphenicol were described (Hawkins and Lederer, 1952; Wolman, 1952) frequent reports and warnings of toxicity have appeared in the literature. Moreover, it is generally agreed that in only comparatively few cases is there no effective alternative to chloramphenicol.

The hypothesis now to be tested is that prescribing of chloramphenicol, for the reasons just indicated, is related to definable characteristics of general practitioners, such as their skill and training.

- Medical Research Council's Social Medicine Research Unit, the London Hospital, London E.1.

\begin{abstract}
Method
Chloramphenicol Prescribing

The prescriptions for chloramphenicol in this study were all for capsules or mixture (palmitate)-that is, preparations for systemic use. Prescriptions containing chloramphenicol for topical use-as in ear and eye drops, eye ointment, and cream -are not considered. The prescriptions analysed were those written by all the general practitioners in several English towns in March or May 1961, but only doctors with (a) 500 or more patients on their lists who $(b)$ issued a total of at least 250 prescriptions during the study month are considered. There were 285 doctors, responsible for 532,000 patients; and they issued 250,000 prescriptions in all during the study period. Of the 285 doctors 182 satisfied criteria $(a)$ and $(b)$. Of the 182 $149(82 \%)$ issued at least one prescription for chloramphenicol during the study month. A total of 1,547 prescriptions for chloramphenicol were issued during this period; this gives a rate of 8.5 prescriptions per doctor per month. Taking the total volume of chloramphenicol used in relation to the popuiation served by the doctors, nearly three prescriptions were issued for every 1,000 patients during the study period. About two-thirds of the prescriptions were issued for courses of 5 to 10 days. Of the remaining one-third most were issued for courses lasting 10 days or more. (A few more were so written that it was not possible to determine the intended duration of the course.) Wade (1966), in a survey of 756 general practitioners in Northern Ireland responsible for $1,411,000$ patients, found that 3,123 prescriptions for chloramphenicol were issued during December 1962. This gives a rate of 4.1 prescriptions per doctor for the month and a rate of 2.2 prescriptions per 1,000 patients, figures which are rather lower than in the present study, though of the same order.
\end{abstract}

